\title{
The Impact of Lymphovascular Space Invasion on Recurrence and Survival in Iranian Patients With Early Stage Endometrial Cancer
}

\author{
Setareh Akhavan ${ }^{\mathrm{a}}$, Azar Ahmadzadeh ${ }^{\mathrm{b}, \mathrm{f}}$, Azamsadat Mousavi ${ }^{\mathrm{a}}$, Mitra Modares Gilany ${ }^{\mathrm{a}}$, \\ Zohreh Kazemic $^{c}$, Fakher Rahim ${ }^{\text {d }}$, Elham Shiralie
}

\begin{abstract}
Background: The aim of this study was to assess the impact of lymphovascular space involvement (LVSI) on recurrence and survival in early stage of endometrial cancer (EC).

Methods: Patients with EC referred to Imam Khomeini Hospital in Tehran were examined and enrolled over a 10-year period (2004 2015). The effect of LVSI on recurrence and overall survival was analyzed using the Kaplan-Meier and log-rank test methods.

Results: A total of 160 patients with early stage EC were identified. Out of 160 women with EC, $135(84.4 \%)$ underwent primary surgery. One hundred and twenty-one $(76.2 \%)$ patients were not found to have LVSI, whereas $38(23.8 \%)$ were found to have LVSI. Of the 38 patients with LVSI, 21 (55.3\%) had endometrioid cell type tumor, $10(26.3 \%)$ had serous, one (2.6\%) had clear cell and six $(15.8 \%)$ had adeno-squamous cell type tumor.

Conclusion: The presence of LVSI represents a factor strongly associated with high risk of recurrence and poor survival in early stage EC. Patients with lower International Federation of Obstetrics and Gynecology (FIGO) stages may be at increased risk of recurrence and a poor overall survival if the pathological findings confirm the presence of LVSI. Thus, LVSI should be added to the traditional factors used to decide whether patients with early stage EC are at high risk of recurrence and adjuvant therapy planning.
\end{abstract}

Manuscript accepted for publication August 02, 2016

aDepartment of Obstetrics and Gynecology, Valieasr Hospital, Tehran University of Medical Sciences, Tehran, Iran

${ }^{b}$ Department of Obstetrics and Gynecology, Imam Khomeini Hospital, Jundishapur University of Medical Sciences, Ahvaz, Iran

'Department of Obstetrics and Gynecology, Taleghani Hospital, Shahid Beheshti University of Medical Sciences, Tehran, Iran

${ }^{\mathrm{d}}$ Health Research Institute, Research Center of Thalassemia and Hemoglobinopathy, Ahvaz Jundishapur University of Medical Sciences, Ahvaz, Iran eDepartment of Obstetrics and Gynecology, Moheb Yas Hospital, Tehran University of Medical Sciences, Tehran, Iran

fCorresponding Author: Azar Ahmadzadeh, Department of Obstetrics and Gynecology, Imam Khomeini Hospital, Jundishapur University of Medical Sciences, Ahvaz, Iran. Email: azar.ahmadzadeh@yahoo.com
Keywords: Lymphovascular space invasion; Prognostic factors; Endometrial cancer; Early stage endometrial cancer

\section{Introduction}

Endometrial cancer (EC) is the most common malignancy of women's genital system which mostly occurs in the post-menopause era and its pathogenicity is increased with increasing age $[1,2]$. Different treatment modalities for patient with EC have been introduced that consist of surgery as the standard treatment, and radiation and hormone therapy as adjuvant therapy [3]. In the past, several studies have tried to assess factors that would impact on the recurrence and survival of EC [4-7]. The most important predictive and prognostic factors in patients with EC include tumor stage, histological grade, stage of disease, depth of myometrial invasion, lymphovascular space involvement (LVSI), and cervical involvement [8-10].

LVSI, a process in which cancer cells invade vascular or lymphatic systems, represents an important prognostic factor in patients with a high incidence of relapses and poor survival $[11,12]$. In spite of many evidences, LSVI was not included in the staging classification for EC reported by the International Federation of Obstetrics and Gynecology (FIGO) till 2009 [13], but it was included in the new and latest one $[14,15]$.

The aim of this study was to assess the impact of LVSI on recurrence and survival in the early stage of EC.

\section{Patients and Methods}

\section{Study design and population}

Patients with EC referred to Imam Khomeini Hospital in Tehran from 2004 to 2015 were examined and enrolled. The study was approved by Tehran University of Medical Sciences (TUMS) ethical committee and all patients signed informed consent before enrollment.

\section{Inclusion criteria}

Women with a histological diagnosis of the early stage of EC 
with age greater than 18 years were included.

\section{Exclusion criteria}

Women with a history of other cancers or synchronous cancer, as well as patients who did not return for follow-up were excluded.

\section{Methods}

Women with a diagnosis of EC after either endometrial biopsy or uterine curettage were subjected to surgical staging. Surgical staging included total abdominal hysterectomy, bilateral salpingo-ovariectomy (BSO), and omental biopsy. Various stages were assigned using the revised FIGO staging system for EC [16]. Pelvic and para-aortic lymph node dissection was performed in the majority of patients. Prognostic factors consisted of patients' age, menopause state and pathological findings that were obtained from tumor grade, histology type, depth of myometrial invasion, LVSI, and cervical involvement. In a few patients, hormone receptor status was assessed. Non-endometrioid types such as papillary serous, clear cell, and adeno-squamous carcinoma, were also enrolled. LVSI was defined as the presence of viable tumor cells in the endothelial-lined channels, either lymphatic or capillaries, outside the tumor mass on H\&Estained sections of uterine specimens. When tumor emboli were found within a space clearly lined by endothelial cells, the tumor was considered as LVSI positive. The migration of malignant cells within the endothelium into the vascular channel was a necessary step in progression of metastatic disease.

\section{Statistical analysis}

The effect of LVSI on recurrence and overall survival was analyzed using the Kaplan-Meier and log-rank test methods. A P value $<0.05$ was used to assess statistical significance. Overall survival was explained as the time from the date of surgery till the date of death. Progression-free survival was defined as the date of surgery until the date of recurrence or progression.

\section{Results}

A total of 160 patients with early stage EC were identified. Out of 160 women with EC, 135 (84.4\%) underwent primary surgery. Endometrioid cell type histology was the most common cell type comprising $75.5 \%$ (120 patients), followed by serous, clear cell carcinoma and adeno-squamous cell type, respectively (Table 1). Figure 1 illustrates a case of LVSI compared to the normal subject. One hundred and twenty-one $(76.2 \%)$ patients were not found to have LVSI, where 38 (23.8\%) were found to have LVSI. Of the 38 patients with LVSI, 21 (55.3\%) had endometrioid cell type tumor, $10(26.3 \%)$ had serous, one $(2.6 \%)$ had clear cell and six $(15.8 \%)$ had adeno-squamous cell type tumor. Eighty-seven patients received adjuvant radiation
Table 1. Patients Characteristics

\begin{tabular}{|c|c|}
\hline Variables & Number or percent \\
\hline Age (median) & 55.5 (range $32-78)$ \\
\hline \multicolumn{2}{|l|}{ Stage of disease } \\
\hline I & $28(17.5 \%)$ \\
\hline IA & $71(44.4 \%)$ \\
\hline IB & $33(20.6 \%)$ \\
\hline III & $28(17.5 \%)$ \\
\hline Total & $160(100 \%)$ \\
\hline \multicolumn{2}{|l|}{ Histology } \\
\hline Endometrioid & $120(75 \%)$ \\
\hline Serous & $17(10.6 \%)$ \\
\hline Clear cell carcinoma & $10(6.2 \%)$ \\
\hline Adeno-squamous carcinoma & $13(8.1 \%)$ \\
\hline Total & $160(100 \%)$ \\
\hline \multicolumn{2}{|l|}{ Grading } \\
\hline $\mathrm{G} 1$ & $72(45 \%)$ \\
\hline G2 & $43(26.8 \%)$ \\
\hline G3 & $24(15 \%)$ \\
\hline Other & $21(13.2 \%)$ \\
\hline Total & $160(100 \%)$ \\
\hline \multicolumn{2}{|l|}{ Lymph vascular space invasion } \\
\hline Yes & $39(24.4 \%)$ \\
\hline No & $121(75.6 \%)$ \\
\hline Total & $160(100 \%)$ \\
\hline \multicolumn{2}{|l|}{ Adjuvant radiation therapy } \\
\hline Yes & $104(65 \%)$ \\
\hline No & $56(35 \%)$ \\
\hline Total & $160(100 \%)$ \\
\hline \multicolumn{2}{|l|}{ Recurrence } \\
\hline Yes & $18(11.3 \%)$ \\
\hline No & $142(88.7 \%)$ \\
\hline Total & $160(100 \%)$ \\
\hline
\end{tabular}

Eighty (11.3\%) patients developed recurrence of disease and only two were found to have LVSI.

therapy, of whom 24 (27.6\%) presented LVSI, and 63 (72.4\%) were not found to have LVSI.

The median overall disease-specific survival in patients with EC and LVSI was 24 months compared with 37 months in those without LVSI $(\mathrm{P}<0.001$, Fig. 2). Therefore, LVSI in our analysis has shown to be a strong predictor of survival.

\section{Discussion}

This study that was aimed to assess the impact of LVSI on recurrence and survival in the early stage of EC, showed LVSI 

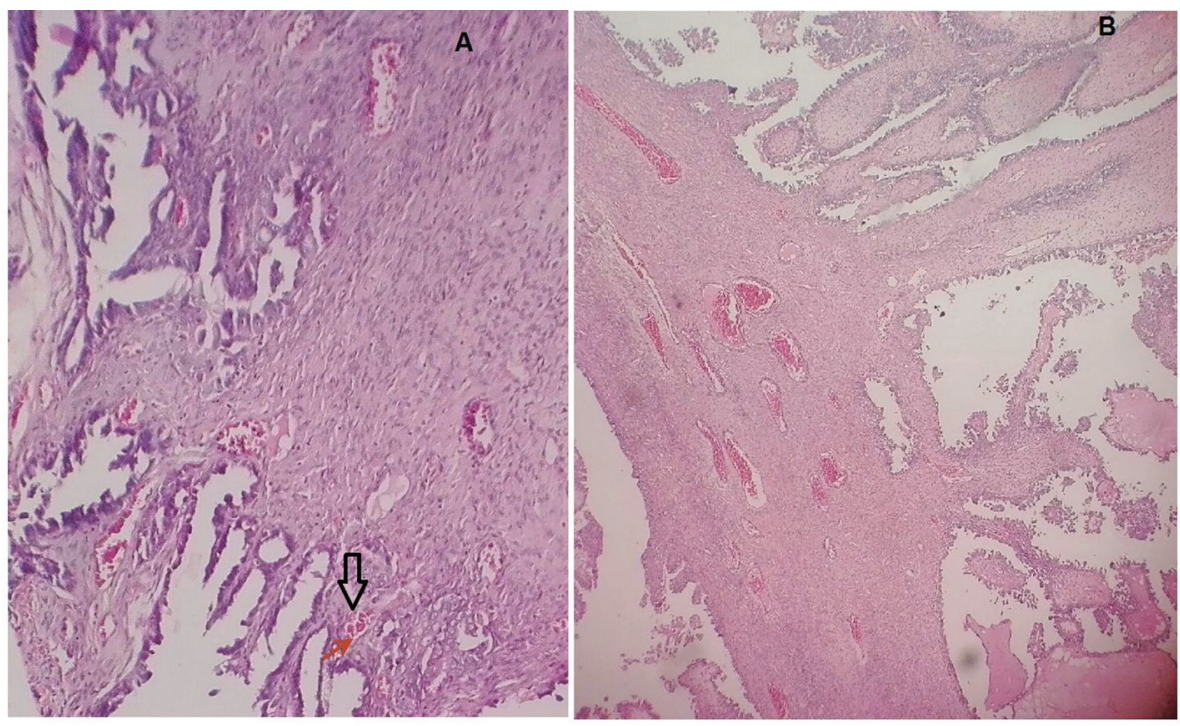

Figure 1. A case of LVSI compared to the normal subject.

to be a strong predictor of survival. EC is considered the most frequent tumor of the gynecologic tract because its incidence is gradually rising [17-19]. Several studies have investigated the role of vascular invasion as a prognostic factor for various cancers, including colorectal [20,21], cervical [22], and breast [23] neoplasms. Moreover, in these malignancies, LVSI is considered as an important adverse and negative prognostic factor taken into consideration in clinical decision-making [24-28]. However, LVSI in EC was still not considered as a negative prognostic factor $[29,30]$, and was not included in the new FIGO staging classification for EC [31-33].

The incidence of LVSI was quite high in our study (23.8\%) compared to previously reported studies (from $2 \%$ to $18 \%$ ) [34-36]. Our finding that was collected from a single institution showed that LVSI is a predictor of a very poor survival and high risk of recurrence in EC. This finding is in agreement

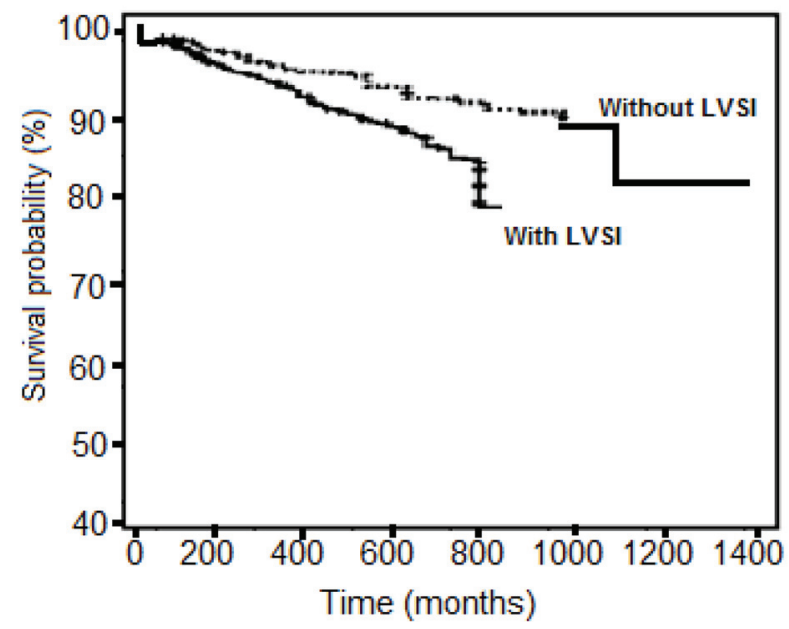

Figure 2. Kaplan-Meier analysis comparing the survival in patients with lymphovascular space involvement (LVSI) with the survival of patients without LVSI. with Loizzi et al on a series of 560 women with EC that also reported similar recurrence rate and poor survival [36]. Two other recent reports confirmed our findings [37, 38].

Other reports have shown neglecting results. Gadducci et al retrospectively assessed the predictive value of LVSI for the risk recurrences in patients with EC and showed that it is associated with a higher risk of distant hematogenous failure [39]. Besides, Rasool et al claimed LVSI not to be predictive of recurrence or poor outcomes [40].

\section{Conclusion}

The presence of LVSI represents a factor strongly associated with high risk of recurrence and poor survival in early stage EC. Patients with lower FIGO stages may be at increased risk of recurrence and a poor overall survival if the pathological findings confirm the presence of LVSI. Thus, LVSI should be added to the traditional factors used to decide whether patients with early stage EC are at high risk of recurrence and adjuvant therapy planning.

\section{Conflicts of Interest}

None.

\section{Source of Funding}

Tehran University of Medical Sciences (TUMS).

\section{References}

1. Weiderpass E, Labreche F. Malignant tumors of the female reproductive system. Saf Health Work. 2012;3(3):166- 
180.

2. Erenel H, Bese T, Sal V, Demirkiran F, Arvas M. Comparison of Diagnostic Accuracies of Serum HE-4 Levels and 3D Power Doppler Angiography Parameters between Benign Endometrial Pathologies and Endometrial Cancer. Asian Pac J Cancer Prev. 2016;17(5):2507-2511.

3. Colombo N, Preti E, Landoni F, Carinelli S, Colombo A, Marini C, Sessa C. Endometrial cancer: ESMO Clinical Practice Guidelines for diagnosis, treatment and followup. Ann Oncol. 2013;24(Suppl 6):vi33-38.

4. Mariani A, Webb MJ, Keeney GL, Aletti G, Podratz KC. Endometrial cancer: predictors of peritoneal failure. Gynecol Oncol. 2003;89(2):236-242.

5. Scholten AN, Smit VT, Beerman H, van Putten WL, Creutzberg CL. Prognostic significance and interobserver variability of histologic grading systems for endometrial carcinoma. Cancer. 2004;100(4):764-772.

6. Odagiri T, Watari H, Hosaka M, Mitamura T, Konno Y, Kato T, Kobayashi N, et al. Multivariate survival analysis of the patients with recurrent endometrial cancer. J Gynecol Oncol. 2011;22(1):3-8.

7. Rauh-Hain JA, Del Carmen MG. Treatment for advanced and recurrent endometrial carcinoma: combined modalities. Oncologist. 2010;15(8):852-861.

8. Sorbe B. Predictive and prognostic factors in definition of risk groups in endometrial carcinoma. ISRN Obstet Gynecol. 2012;2012:325790.

9. Uharcek P. Prognostic factors in endometrial carcinoma. J Obstet Gynaecol Res. 2008;34(5):776-783.

10. Ivanov I. [Survival, prognostic factors and modern tendencies in adjuvant treatment of diagnosed endometrial cancer patients with or without lymph node dissection]. Akush Ginekol (Sofiia). 2009;48(Suppl 1):3-11.

11. Zhang Y, Zhao D, Gong C, Zhang F, He J, Zhang W, Zhao $\mathrm{Y}$, et al. Prognostic role of hormone receptors in endometrial cancer: a systematic review and meta-analysis. World J Surg Oncol. 2015;13:208.

12. Kim H, Kim M, Kwak C, Kim HH, Ku JH. Prognostic significance of lymphovascular invasion in radical cystectomy on patients with bladder cancer: a systematic review and meta-analysis. PLoS One. 2014;9(2):e89259.

13. Kim HS, Song YS. International Federation of Gynecology and Obstetrics (FIGO) staging system revised: what should be considered critically for gynecologic cancer? J Gynecol Oncol. 2009;20(3):135-136.

14. Hod M, Kapur A, Sacks DA, Hadar E, Agarwal M, Di Renzo GC, Cabero Roura L, et al. The International Federation of Gynecology and Obstetrics (FIGO) Initiative on gestational diabetes mellitus: A pragmatic guide for diagnosis, management, and care. Int J Gynaecol Obstet. 2015;131(Suppl 3):S173-211.

15. Hanson MA, Bardsley A, De-Regil LM, Moore SE, Oken E, Poston L, Ma RC, et al. The International Federation of Gynecology and Obstetrics (FIGO) recommendations on adolescent, preconception, and maternal nutrition: "Think Nutrition First". Int J Gynaecol Obstet. 2015;131(Suppl 4):S213-253.

16. Abu-Rustum NR, Zhou Q, Iasonos A, Alektiar KM, Leitao MM, Jr., Chi DS, Sonoda Y, et al. The revised 2009
FIGO staging system for endometrial cancer: should the 1988 FIGO stages IA and IB be altered? Int J Gynecol Cancer. 2011;21(3):511-516.

17. Greenlee RT, Hill-Harmon MB, Murray T, Thun M. Cancer statistics, 2001. CA Cancer J Clin. 2001;51(1):15-36.

18. Bal DG. Cancer statistics 2001: quo vadis or whither goest thou? CA Cancer J Clin. 2001;51(1):11-14, 12.

19. Kellert IM, Botterweck AA, Huveneers JA, Dirx MJ. Trends in incidence of and mortality from uterine and ovarian cancer in Mid and South Limburg, The Netherlands, 1986-2003. Eur J Cancer Prev. 2009;18(1):85-89.

20. Resch A, Harbaum L, Pollheimer MJ, Kornprat P, Lindtner RA, Langner C. Inclusion of cytological features in tumor grading improves prognostic stratification of patients with colorectal cancer. Int $\mathrm{J}$ Colorectal Dis. 2016;31(3):535-541.

21. Schneider NI, Langner C. Prognostic stratification of colorectal cancer patients: current perspectives. Cancer Manag Res. 2014;6:291-300.

22. Siva S, Herschtal A, Thomas JM, Bernshaw DM, Gill S, Hicks RJ, Narayan K. Impact of post-therapy positron emission tomography on prognostic stratification and surveillance after chemoradiotherapy for cervical cancer. Cancer. 2011;117(17):3981-3988.

23. Soerjomataram I, Louwman MW, Ribot JG, Roukema JA, Coebergh JW. An overview of prognostic factors for long-term survivors of breast cancer. Breast Cancer Res Treat. 2008;107(3):309-330.

24. Tian YF, Zhou H, Yu G, Wang J, Li H, Xia D, Xiao HB, et al. Prognostic significance of lymphovascular invasion in bladder cancer after surgical resection: A meta-analysis. J Huazhong Univ Sci Technolog Med Sci. 2015;35(5):646655.

25. Li P, He HQ, Zhu CM, Ling YH, Hu WM, Zhang XK, Luo RZ, et al. The prognostic significance of lymphovascular invasion in patients with resectable gastric cancer: a large retrospective study from Southern China. BMC Cancer. 2015;15:370.

26. Chen M, Jin Y, Bi Y, Li Y, Shan Y, Pan L. Prognostic significance of lymphovascular space invasion in epithelial ovarian cancer. J Cancer. 2015;6(5):412-419.

27. Hwang JE, Hong JY, Kim JE, Shim HJ, Bae WK, Hwang EC, Jeong $\mathrm{O}$, et al. Prognostic significance of the concomitant existence of lymphovascular and perineural invasion in locally advanced gastric cancer patients who underwent curative gastrectomy and adjuvant chemotherapy. Jpn J Clin Oncol. 2015;45(6):541-546.

28. Lee JH, Kim MG, Jung MS, Kwon SJ. Prognostic significance of lymphovascular invasion in node-negative gastric cancer. World J Surg. 2015;39(3):732-739.

29. Briet JM, Hollema H, Reesink N, Aalders JG, Mourits MJ, ten Hoor KA, Pras E, et al. Lymphvascular space involvement: an independent prognostic factor in endometrial cancer. Gynecol Oncol. 2005;96(3):799-804.

30. Gemer O, Arie AB, Levy T, Gdalevich M, Lorian M, Barak F, Anteby E, et al. Lymphvascular space involvement compromises the survival of patients with stage I endometrial cancer: results of a multicenter study. Eur J Surg Oncol. 2007;33(5):644-647. 
31. Benedet JL, Bender H, Jones H, 3rd, Ngan HY, Pecorelli S. FIGO staging classifications and clinical practice guidelines in the management of gynecologic cancers. FIGO Committee on Gynecologic Oncology. Int J Gynaecol Obstet. 2000;70(2):209-262.

32. Prat J. FIGO's staging classification for cancer of the ovary, fallopian tube, and peritoneum: abridged republication. J Gynecol Oncol. 2015;26(2):87-89.

33. Lewin SN. Revised FIGO staging system for endometrial cancer. Clin Obstet Gynecol. 2011;54(2):215-218.

34. Nofech-Mozes S, Ghorab Z, Ismiil N, Ackerman I, Thomas G, Barbera L, Covens A, et al. Endometrial endometrioid adenocarcinoma: a pathologic analysis of 827 consecutive cases. Am J Clin Pathol. 2008;129(1):110-114.

35. Hanson MB, van Nagell JR, Jr., Powell DE, Donaldson ES, Gallion H, Merhige M, Pavlik EJ. The prognostic significance of lymph-vascular space invasion in stage I endometrial cancer. Cancer. 1985;55(8):1753-1757.

36. Loizzi V, Cormio G, Lorusso M, Latorre D, Falagario M, Demitri P, Scardigno D, et al. The impact of lymph vascular space invasion on recurrence and survival in patients with early stage endometrial cancer. Eur J Cancer Care
(Engl). 2014;23(3):380-384.

37. Guntupalli SR, Zighelboim I, Kizer NT, Zhang Q, Powell MA, Thaker PH, Goodfellow PJ, et al. Lymphovascular space invasion is an independent risk factor for nodal disease and poor outcomes in endometrioid endometrial cancer. Gynecol Oncol. 2012;124(1):31-35.

38. Simpkins F, Papadia A, Kunos C, Michener C, Frasure $\mathrm{H}$, AbuShahin F, Mariani A, et al. Patterns of recurrence in stage I endometrioid endometrial adenocarcinoma with lymphovascular space invasion. Int J Gynecol Cancer. 2013;23(1):98-104.

39. Gadducci A, Cavazzana A, Cosio S, C DIC, Tana R, Fanucchi A, Teti G, et al. Lymph-vascular space involvement and outer one-third myometrial invasion are strong predictors of distant haematogeneous failures in patients with stage I-II endometrioid-type endometrial cancer. Anticancer Res. 2009;29(5):1715-1720.

40. Rasool N, Fader AN, Seamon L, Neubauer NL, Shahin FA, Alexander HA, Moore K, et al. Stage I, grade 3 endometrioid adenocarcinoma of the endometrium: an analysis of clinical outcomes and patterns of recurrence. Gynecol Oncol. 2010;116(1):10-14. 